\title{
La construcción social de las figuras de la represión en Argentina. Conflictos y disputas a partir del testimonio de Julián "El Laucha" Corres en el Juicio por la Verdad de Bahía Blanca (1999) ${ }^{1}$
}

\author{
The social construction of the figures of the repression \\ in Argentina. Conflicts and disputes based on the \\ testimony of Julián "El Laucha" Corres in the Trial \\ for the Truth of Bahía Blanca (1999)
}

Enrique Salvador Andriotti Romanin ${ }^{2}$

Fecha de recepción: 5 de septiembre de 2020

Fecha de aceptación: 23 de noviembre de 2020

\begin{abstract}
1- El presente artículo es una continuidad de una investigación que ya ha tenido avances publicados en 2015 y 2017. En 2015 se analizaron las estrategias judiciales desplegadas por los integrantes de las Fuerzas Armadas, retirados o en actividad, que brindaron testimonio en el Juicio por la Verdad de Bahía Blanca. En 2017 se analizó el discurso de un integrante de las Fuerzas Armadas involucrado en la represión, Julián Oscar Corres, con relación al accionar de las Fuerzas Armadas durante el terrorismo de Estado. En este artículo se indaga en una dimensión no analizada anteriormente: los conflictos y disputas resultantes de la participación de Corres en la sala de audiencias y su incidencia en la construcción de la figura de represor.

2- Nacionalidad: Argentina. Grado: Doctorado en Ciencias Sociales. Adscripción: Universidad Nacional de Mar del Plata, Argentina.(D) ORCID: https://orcid.org/0000-0002-3386-6092. Correo electrónico: andriottiromaninenrique1@gmail.com




\section{Resumen}

A finales de la década de los años 90 se realizó en Bahía Blanca, Argentina, uno de los denominados Juicios por la Verdad. En ese marco, el teniente coronel Julián Oscar Corres se convirtió en el primer militar argentino en actividad en brindar testimonio judicial tras las leyes y decretos que impidieron la persecución penal a los perpetradores de las violaciones a los derechos humanos cometidas entre $1976 y$ 1983. En este trabajo se analizan las disputas y conflictos ocurridos en torno a la participación de Corres en este juicio con el objetivo de aportar a la comprensión de los procesos sociales y políticos que intervinieron en la construcción de la figura de los perpetradores de crímenes durante el terrorismo de Estado en la Argentina. Para la realización de esta investigación se trabajó con una metodología de análisis cualitativa, basada en el estudio de un caso a partir de distintas fuentes audiovisuales, periodísticas y entrevistas en profundidad a operadores judiciales y testigos sobrevivientes que participaron como testigos en el Juicio por la Verdad de Bahía Blanca.

Palabras clave: Argentina, juicios, represores, memorias, terrorismo de Estado

\section{Abstract}

At the end of the 90s, one of the so-called Truth Trials was held in Bahía Blanca, Argentina. Within this context, Lieutenant Colonel Julián Oscar Corres became the first active Argentine military officer to give judicial testimony following the laws and decrees that prevented criminal prosecution of those responsible for the human rights violations committed between 1976 and 1983. This paper analyzes the disputes and conflicts that occurred around the participation of Corres in this trial with the aim of contributing to the understanding of the social and political processes that intervened in the construction of the figure of the perpetrators of crimes during State terrorism in Argentina. To carry out this research, we worked with a qualitative analysis methodology based on different audiovisual and journalistic sources and in-depth interviews to judicial operators and surviving witnesses who participated as witnesses in the Bahia Blanca Truth Trial.

Keywords: Argentina, trials, repressors, memories, state terrorism 


\section{Introducción}

E 115 de diciembre de 1999 Julián Oscar Corres se retiró de la sala de audiencias de la Cámara Federal de Apelaciones de Bahía Blanca ${ }^{3}(\mathrm{CFB})$, de Argentina, tras participar como testigo en el Juicio por la Verdad. Su salida se produjo acompañada de insultos por parte de sobrevivientes y familiares de víctimas del terrorismo de Estado, luego de su negativa a realizar dos careos ${ }^{4}$ con testigos que lo señalaron como partícipe de operativos clandestinos en el marco de la "guerra antisubversiva" y de perpetrar abusos y torturas en Centro Clandestino de Detención denominado "La Escuelita" (CCD Escuelita) ${ }^{5}$.

Por entonces, Corres era un militar de carrera que ostentaba el grado de teniente coronel del Ejército Argentino y cumplía funciones en el Destacamento de Inteligencia del Ejército situado en la ciudad de Río Gallegos, de la provincia de Santa Cruz. En este sentido, su accionar durante el terrorismo de Estado era desconocido para la mayor parte de la sociedad argentina. Sin embargo, tras su presentación en el juicio, esto último comenzaría a cambiar y el militar se transformaría en una de las figuras públicas de la represión en la ciudad de Bahía Blanca.

El presente artículo indaga en la participación de Corres en el Juicio por la Verdad de Bahía Blanca con el objetivo de aportar a la comprensión de cómo se manifestaron en el escenario judicial los miembros de las Fuerzas Armadas tras el retorno de la democracia y analizar su impacto en los procesos de elaboración del pasado reciente y en la construcción social de la figura del "represor"6 en Argentina. El presupuesto que se sostiene en este artículo es que los conflictos resultantes de la participación de Corres en la sala de audiencias del Juicio por la Verdad contribuyeron a la conformación de una representación de éste como una de las figuras de la represión en Bahía Blanca.

Para la realización de esta investigación se trabajó con una metodología de análisis cualitativa, entendiendo a ésta como un acercamiento subjetivo e interpretativo al estudio de la vida humana que focaliza en cómo es construido e interpretado el mundo social por sus actores, produciendo datos descriptivos de las propias palabras de las personas, habladas o escritas, y de la conducta observable (Taylor y Bogdan, 1987). Dentro de este paradigma, se priorizó el enfoque del estudio de caso con el objetivo de centrarnos en la comprensión de la dinámica conflictual que se produjo en torno a las declaraciones brindadas por Corres en el marco de un proceso judicial penal orientado a la búsqueda de la verdad acerca del destino

3- La Cámara Federal de Apelaciones es la máxima instancia de grado de la Justicia Federal de Bahía Blanca, Argentina. La ciudad de Bahía Blanca se encuentra situada al sur de la provincia de Buenos Aires. Durante la dictadura militar (1976-

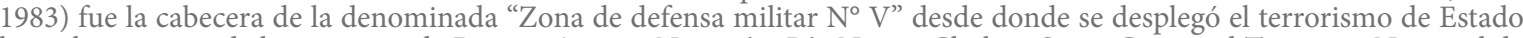
hacia la parte sur de la provincia de Buenos Aires, y Neuquén, Río Negro, Chubut, Santa Cruz, y el Territorio Nacional de Tierra del Fuego. Las fuerzas que desplegaron la represión pertenecían orgánicamente al V Cuerpo de Ejército.

4- El careo es una figura prevista en el Derecho Procesal Penal argentino y tiene por objeto aclarar los aspectos contradictorios de declaraciones de los testigos en un proceso penal. Se realiza mediante la confrontación, ante el juez o tribunal, y en presencia del imputado, de quien ha declarado en su contra, para que aclare sus dichos que pueden haber sido considerados contradictorios. Al respecto véase Palacio Lino, 2002.

5- Instalación secreta que funcionó en las inmediaciones del V Cuerpo de Ejército. Fue utilizada entre 1976 y 1979 por las Fuerzas Armadas para el secuestro, tortura y desaparición de personas.

6- Modo coloquial del lenguaje político argentino utilizado para nombrar a miembros de fuerzas represivas. Tras la dictadura militar, esta palabra se utilizó por parte de los familiares y víctimas de los desaparecidos para denominar a los miembros de las fuerzas de seguridad que cometieron crímenes, secuestros y torturas contra ciudadanos y ciudadanas durante el terrorismo de Estado en Argentina. 
de ciudadanos y ciudadanas desaparecidos durante la última dictadura militar en Argentina.

En la investigación que dio origen a este artículo se utilizaron distintas fuentes de datos. En primer lugar, se analizaron los videos de las audiencias del Juicio por la Verdad de Bahía Blanca donde Corres brindó testimonio o participó. La filmación de las declaraciones fue realizada por la CFB de Bahía Blanca durante el juicio y forman parte del expediente judicial. Las mismas se encuentran disponibles para consulta en el Fondo Audiovisual Juicio por la Verdad - Bahía Blanca, de la Asociación Civil Memoria Abierta, en la ciudad de Buenos Aires, Argentina. La importancia del análisis de las audiencias radica en que permitieron observar los conflictos judiciales suscitados en la sala de audiencias en torno al testimonio del militar. En segundo lugar, se analizaron las noticias publicadas por diarios de circulación local y nacional con relación a la participación de Corres. Para ello se relevaron los diarios de mayor tirada de circulación nacional en Argentina durante el periodo de realización de este juicio (Clarín, La Nación, Diario Popular y Página 12) y el único de Bahía Blanca (La Nueva Provincia) en las semanas previas y posteriores a la declaración de este militar. La selección de los diarios de mayor tirada nacional se realizó priorizando su impacto y cobertura. El archivo de los diarios consultados se encuentra disponible en la Biblioteca del Congreso de la Nación Argentina. El análisis de las noticias permitió identificar las posiciones de diferentes actores y los sentidos asignados por la prensa a los dichos del militar en un contexto específico. En tercer lugar, se reconstruyó la historia de este juicio mediante la técnica de entrevistas en profundidad a referentes de organizaciones de derechos humanos y distintos operadores judiciales que intervinieron en él. Se realizaron cinco entrevistas semiestructuradas de tres horas promedio de duración cada una. La primera entrevista fue con el Fiscal de la CFB quien, posteriormente, facilitó el contacto con la abogada querellante. Finalmente, por intermedio de esta última, se estableció contacto con tres testigos sobrevivientes que habían brindado testimonio en el juicio. Mediante las entrevistas se construyó un mapa de actores y se identificaron los conflictos que se desarrollaron en torno a la participación de Corres en el Juicio por la Verdad. Finalmente, se analizaron documentos de distintas organizaciones de derechos humanos de Bahía Blanca a fin de identificar las actividades realizadas a partir de las declaraciones del militar. Los mismos fueron facilitados por los entrevistados.

\section{Las investigaciones sobre la palabra de los represores de la dictadura militar Argentina y en el escenario judicial}

Los trabajos en torno a las memorias sociales acerca del terrorismo de Estado en Argentina constituyen un área de investigaciones que se ha desarrollado paulatinamente y de manera creciente en las últimas décadas. Aunque la mayoría de estas investigaciones se concentró mayormente en pensar los efectos y las luchas por la memoria social de lo ocurrido desplegadas por miembros de organizaciones de la sociedad civil (en especial del Movimiento de derechos humanos), también podemos encontrar algunas investigaciones en torno a las memorias militares sobre la represión. Estas se han concentrado en indagar en las características de la construcción de una memoria del pasado en el discurso de los militares (Hershberg y Agüero, 2005; Marchesi, 2005; Lorenz, 2007), en los procesos de transmisión de las mismas a los jóvenes oficiales del Ejército argentino (Badaro, 2009; Salvi, 2012), en el discurso institucional de las Fuerzas Armadas (Canelo, 2010), en los núcleos ideológicos del discurso militar (Lorenz, 
2002 y 2007; Vezzetti, 2002), las repercusiones acerca de la muerte de los dictadores (Garibian, 2016), la participación de exrepresores en programas televisivos (Feld, 2001 y 2009) o en los relatos de los oficiales retirados (Robben, 2008) como temas de importancia. Si bien estos trabajos han permitido comprender diferentes aspectos acerca de las memorias militares, el análisis sistemático de las declaraciones públicas de los militares involucrados con la represión en Argentina y sus repercusiones constituye un tema poco explorado por las investigaciones académicas.

Los trabajos de Feld y Salvi (2016 y 2019) han abierto una línea de exploración centrada en la palabra pública de los represores. Para estas autoras, el estudio de las manifestaciones de los represores supone lidiar con problemas de orden teórico, político y ético que deben ser abordados pues "esa palabra controvertida participa en las luchas memoriales y políticas del presente, porque tiene efectos y genera sentidos en diversos ámbitos sociales, que su estudio es relevante precisamente para sostener y apoyar las luchas de las víctimas y su necesidad de reparación y justicia" (2016, p. 3). Estas autoras destacan la importancia de comprender los efectos de las declaraciones públicas de los represores y su relación con las coyunturas históricas, políticas y memoriales en las que se producen, así como los escenarios en que tiene lugar, pues nos permiten aproximarnos a "las mediaciones institucionales y los procesos de elaboración de la violencia del pasado reciente que colectivamente se han producido" (Feld y Salvi, 2019, p. 33). En esta línea, se considera de importancia aportar a un área de vacancia que consiste en el análisis de las declaraciones efectuadas en el escenario judicial, en tanto este constituye un ámbito privilegiado en la construcción de discursos sobre el pasado y que incide en las posibilidades de la sociedad ${ }^{7}$ de elaborar el pasado traumático (Feierstein, 2012) a partir de la declaración de un militar en actividad, que se dio en una modalidad de justicia transicional que se conoció como Juicios por la Verdad.

Estos juicios se realizaron en el ámbito de la justicia penal argentina con el objetivo de conocer la verdad acerca del destino de ciudadanos detenidos y desaparecidos durante el terrorismo de Estado. Fueron el resultado de una estrategia jurídica novedosa elaborada por los abogados de algunas organizaciones de derechos humanos que permitió reactivar en distintas instancias de la justicia penal federal la búsqueda de la verdad acerca de los desaparecidos en un contexto definido por la vigencia de las "Leyes de Impunidad".

La realización de las audiencias en distintas ciudades del país, permitió el tratamiento judicial del pasado de terrorismo de Estado en una escala subnacional que generó tensiones y conflictos pues indagaron en las tramas sociales y políticas que permitieron el despliegue represivo a escala local (Rauschberg, 2013). En los hechos, estos juicios se transformaron en un escenario de lucha por el sentido de lo ocurrido entre los familiares de desaparecidos y sobrevivientes y los militares retirados o en actividad (Andriotti Romanin, 2013). Por este motivo, y también por las características que asumieron, convocaron la atención de los medios de comunicación y, con ello, de una parte de la sociedad argentina.

En esta línea, el análisis de los conflictos entre los actores que se dieron cita en el marco de las audiencias de esta modalidad judicial permite comprender la dinámica de interacción entre lo que ocurrió

7- Michel Foucault ha señalado la importancia de estudiar las prácticas judiciales y la verdad en tanto "son algunas de las formas empleadas por nuestra sociedad para definir tipos de subjetividad, formas de saber y, en consecuencia, relaciones entre el hombre y la verdad que merecen ser estudiadas" (2011, p.16).

8- En Argentina este término se utiliza para hacer referencia a las leyes 23.591 de "Punto final" y 23.492 de "Obediencia Debida" y a una serie de indultos presidenciales que desde 1990 hasta mediados de 2005 clausuraron la posibilidad de persecución penal contra los perpetradores de crímenes durante el periodo de terrorismo de Estado. 
al interior de la sala de audiencias y por fuera de ellas, los usos de los testimonios por parte de actores sociales y circulación de los mismos, las disputas en torno a cómo recordar lo ocurrido durante la represión estatal en la última dictadura militar, aproximándonos a los procesos políticos y judiciales que intervinieron en la construcción de la figura del "represor" en Argentina.

\section{E1 Juicio por la Verdad de Bahía Blanca}

Desde mediados de la década de los 90 en Argentina se produjo un retorno a la esfera pública de distintos debates acerca de la violencia política y del accionar de miembros de las Fuerzas Armadas durante el terrorismo de Estado. Impulsados por actores sociales y políticos, en un contexto definido por las declaraciones de exmiembros de las Fuerzas Armadas que reconocieron la comisión de crímenes, del vigésimo aniversario del golpe militar y de un proceso judicial llevado adelante en la sala V de la Audiencia Nacional Española para conocer el destino de ciudadanos españoles desaparecidos entre 1976 y 1983.

El primero de estos juicios se inició en la ciudad de La Plata en abril de 1998 y un año después comenzó el segundo en Bahía Blanca. La realización de este juicio en la Cámara Federal de esta ciudad ${ }^{9}$ permitió observar, desde un comienzo, la existencia de un conflicto entre actores sociales en relación a cómo lidiar con el pasado y el lugar diferencial otorgado por estos al Juicio por la Verdad: por un lado, los sobrevivientes y familiares de los desaparecidos, impulsaban ${ }^{10}$ el juicio por la Verdad como una instancia donde tendrían una oportunidad para hablar públicamente del pasado, contar lo que les ocurrió y trabajar distintos emprendimientos para dar a conocer su verdad a la sociedad. Por otro lado, los militares y los actores civiles vinculados al terrorismo de Estado se oponían a la realización del juicio por considerarlo parcial y lo interpretaban como la continuidad de una persecución iniciada contra ellos, tras el retorno a la democracia, por exguerrilleros y sus aliados a quienes habían vencido en la "Guerra Antisubversiva”. Entre los últimos se destacó el principal diario de la ciudad de Bahía Blanca, La Nueva Provincia (LNP) ${ }^{11}$. Este manifestó su oposición temprana al juicio mediante una campaña de desprestigio hacia el fiscal de la CFB, Hugo Omar Cañón ${ }^{12}$.

Esta campaña comenzó el 21 de noviembre de 1999. Ese día, LNP publicó una editorial en la que refería al juicio que se desarrollaba en la Audiencia Nacional española y cuestionando el sentido de la

9- La CFB tenía antecedentes en el tratamiento de crímenes durante el terrorismo de Estado: en 1986, en el marco de la causa 11/86, investigó los delitos cometidos en la jurisdicción del Vo Cuerpo de Ejército. Con la sanción de los Indultos se terminaron las actuaciones de esta causa.

10- Miarta Mantaras, la abogada de la delegación Neuquén Bahía Blanca de la Asamblea Permanente por los Derechos Humanos (APDH Neuquen - Bahía Blanca), era una de las principales promotoras del juicio. Desde su creación en 1985 la APDH desarrollo una intensa labor denunciando los crímenes del terrorismo de Estado en Bahía Blanca.

11- LNP había sido uno de los principales promotores del golpe de Estado de 1976. Durante el terrorismo de Estado LNP acompañó el ejercicio represivo mediante la difusión de información falsa acerca de enfrentamientos o "subversivos abatidos". Con el retorno de la democracia, LNP continuó reivindicando la "guerra antisubversiva” y cuestionado las distintas iniciativas en torno a la búsqueda de la verdad y justicia respecto a los desaparecidos. Al respecto véase Zapata (2013).

12- Cañón estaba identificado con la demanda de justicia por los crímenes cometidos durante el terrorismo de Estado. Anteriormente, como fiscal de la CFB, se había manifestado por la inconstitucionalidad de la Ley de Obediencia Debida y los Indultos. Además, había sido el único alto funcionario del Poder Judicial Federal argentino que brindó testimonio y aportó información documental en la causa que, desde 1996, llevaba adelante la sala V de la Audiencia Nacional de España por los casos de ciudadanos españoles desaparecidos entre 1976 y 1983. 
participación del fiscal de la CFB en dicha instancia y planteando el accionar de la justicia "como la continuación de la guerra" (La Nueva Provincia, 21/11/99).

El cuestionamiento a la figura del fiscal, un día antes del inicio del Juicio por la Verdad, permitió observar que LNP era utilizado como un vehículo de memoria para disputar el sentido de lo ocurrido entre 1976 y 1983. Esto no era una novedad: LNP había sido uno de los pilares ideológicos del terrorismo de Estado y, desde el retorno a la democracia, desde sus páginas exmilitares y civiles se manifestaron reivindicando lo actuado durante la "Guerra Antisubversiva", mientras bregaban por una "Verdad Completa"13 y disputaban la interpretación del pasado sostenida por organizaciones del movimiento de derechos humanos. En virtud de la centralidad de LNP en el sistema de medios de la ciudad, sus notas funcionaban como una usina de discurso, que era amplificada por otros medios audiovisuales y radiales vinculados al grupo La Nueva Provincia ${ }^{14}$.

La primera audiencia del juicio se realizó el día 22 de noviembre de 1999. Los primeros testigos fueron dos sobrevivientes y la madre de un desaparecido. Para estos testigos, participar en el juicio, "decir la verdad" en el escenario judicial frente a quienes eran encargados en el sistema legal argentino de impartir justicia, constituyó un modo de denunciar públicamente la continuidad de una situación de injusticia. Por ende, testimoniar en este juicio era experimentado por ellos como un deber moral, un mandato orientado a cuestionar la impunidad existente, aun cuando no se pudiera perseguir penalmente a los responsables ${ }^{15}$. En sus testimonios, mencionaban las características que asumió la represión, narraban lo que les había ocurrido y buscaban transmitir el horror al que fueron sometidos. Sus respuestas ante las preguntas del fiscal se transformaron en extensas declaraciones, la imagen de la "Guerra Antisubversiva" se diluía. Mediante sus palabras, estos testigos situaron a los militares en acciones represivas clandestinas, los vincularon al CCD Escuelita y denunciaron los tormentos y atrocidades perpetrados hacia ellos. Su lugar de enunciación era el de los afectados, el de las víctimas, que señalaban a los perpetradores de la represión.

Para los familiares y sobrevivientes, la difusión de estas audiencias constituyó una tarea central. Por intermedio del fiscal de la CFB solicitaron a los jueces que los testimonios del juicio fueran transmitidos mediante parlantes situados fuera del edificio de la CFB con el objetivo de que los testimonios llegaran a un público más amplio. Así, buscaban que la verdad que emergía en el juicio trascendiera más allá de la sala de audiencias. Para lograr este objetivo, recurrieron a una estrategia basada en movilizar recursos y redes personales para lograr que cursos de estudiantes de colegios secundarios de la ciudad y también de la Universidad Nacional del Sur concurrieran a la primera audiencia. El resultado fue que trescientos estudiantes acompañaron el desarrollo de la primera audiencia. Esto les permitió generar un hecho político en torno al juicio y otorgar visibilidad pública a sus demandas.

13- La demanda de una "Verdad Completa" por parte de estos sectores buscaba denunciar la existencia de una "verdad parcial" y una memoria social "parcial" sobre lo ocurrido durante la década del 70, construida por las organizaciones de derechos humanos en torno a los desaparecidos. De este modo, buscaban señalar la responsabilidad de las organizaciones armadas en la violencia política y en la comisión de crímenes, reivindicar la "Guerra Antisubversiva” y reforzar la imagen de las Fuerzas Armadas como una institución damnificada por la violencia política. Al respecto, véase Salvi (2012).

14- LNP era el diario más antiguo de la ciudad y uno de los más importantes del Sur de la provincia de Buenos Aires, Argentina. Mantenía vínculos muy estrechos especialmente con LU2 Radio Bahía Blanca, que pertenecía a los mismos dueños y el Canal 9 de televisión local, donde los dueños de LNP poseían participación accionaria.

15- Esto fue reconstruido a partir de distintas entrevistas realizadas a sobrevivientes que brindaron testimonio en el Juicio por la Verdad de Bahía Blanca. 
En simultáneo a los testimonios de los sobrevivientes y familiares, brindaron testimonio dos Aspirantes a Oficiales de Reserva ${ }^{16}$ (AOR) que cumplieron funciones en el V Cuerpo de Ejército entre 1976 y 1977. En sus declaraciones, estos testigos sostuvieron los dichos que habían brindado en 1987, en el marco de la causa 11/86, y aportaron nueva información: con precisión, señalaron los nombres y funciones de algunos militares que se desempeñaron en el CCD Escuelita, brindaron información acerca de distintas situaciones que compartieron con éstos y les atribuyeron una activa participación en la "Guerra Antisubversiva".

La primera reacción frente a estos testimonios provino del diario LNP. En sus crónicas acerca del juicio señaló que los testigos AOR solo dijeron "los mismos nombres que en 1986" y relativizó los dichos de los sobrevivientes al señalar que solo "eran una versión de los hechos", pero también incitó a los militares a tomar recaudos antes de presentarse a declarar (LNP, 30/11/99).

En este contexto se produjo la comparecencia a brindar testimonio de los primeros militares retirados. Estos adoptaron una estrategia de participación sin cooperación orientada a obstaculizar el desarrollo del juicio (Andriotti Romanin, 2015). La misma se estructuró a partir de una estrategia tendiente a intentar evitar la citación mediante recursos procesales y, una vez frente a los jueces, la adopción de una postura reticente a la hora de testimoniar, evitando brindar información, utilizando respuestas evasivas, enmarcando su accionar en el marco de la "Guerra Antisubversiva" y evitando referirse a los desaparecidos. Esta postura generó controversias con la fiscalía y la querella que denunciaron la falta de cooperación y a uno de ellos por falso testimonio. Es en ese marco que la fiscalía decidió dar un paso más y convocar a un militar en actividad que había sido mencionado en los testimonios de los exconscriptos AOR y de los militares retirados: Julián Oscar Corres.

El apellido de Corres era conocido por los miembros del tribunal. Había sido mencionado por el principal responsable de la represión en Bahía Blanca, el General Acdel Vilas, como un suboficial vinculado a tareas de inteligencia en el combate contra "la subversión"17. Sin embargo, para la sociedad argentina era un desconocido. En este aspecto, la posible comparecencia a testimoniar por parte del militar cobraba un significado mayor pues, por un lado, nunca había sido citado a declarar con anterioridad y, por otro, porque era el primer militar con rango de oficial citado a declarar en relación a lo sucedido durante el terrorismo de Estado desde la promulgación de los indultos.

\subsection{La primera metamorfosis de Corres: "El Laucha"}

El 13 de diciembre de 1999 fue la fecha que fijó la CFB para que Julián Oscar Corres se presentara a brindar declaración testimonial en el Juicio por la Verdad. Esa mañana, LNP publicó una nota en su tapa donde señalaba que Corres se abstendría de brindar testimonio y que, en cambio, daría inicio a

16- Figura prevista en el artículo 17 de la ley no 17.531 de servicio militar obligatorio. Conocidos como AOR, eran profesionales, que tras un pedido de prórroga eran incorporados al servicio militar como oficiales en comisión. No eran oficiales de carrera, pero tenían trato y desempeñaban funciones como éstos.

17- En 1987 el General Acdel Vilas fue citado a brindar declaración indagatoria ante la CFB. A diferencia de otros oficiales de alto rango, ante los jueces, Vilas reivindicó el accionar de las Fuerzas Armadas en la "Lucha Antisubversiva" aportó documentación, Directivas y Reglamentos. Asimismo, aportó nombres del personal militar del V Cuerpo de Ejército que se desempeñó en "operaciones antisubversivas" y reconoció la existencia de distintos "Lugares de reunión de detenidos", uno de ellos conocido como "La Escuelita". Sin embargo, no reconoció la tortura, ni la eliminación de prisioneros y negó conocer el destino de los desaparecidos. 
una contraofensiva judicial. Además, señalaba que esta estaba "acordada por el Ejército y el Gobierno de Fernando de la Rúa ${ }^{18}$ que apunta a llevar a la Corte Suprema de Justicia la totalidad de los procesos que se vienen desarrollando en distintas cámaras y juzgados federales para esclarecer el destino de los desaparecidos" (LNP, 13/12/99). De este modo, LNP se erigía como un vocero del actor militar que anticipaba el inicio de una nueva estrategia judicial en torno al Juicio por la Verdad.

Este anuncio de una "contraofensiva" era una manera de amedrentar a los jueces que, en ese marco, podrían ser objeto de cuestionamientos y, al mismo tiempo, servía para dar una señal hacia los militares retirados o en actividad acerca del inicio de una respuesta política y judicial tendiente a obturar la revisión del pasado. La apelación a una "contraofensiva" enmarcaba lo ocurrido en el juicio en una retórica belicista, coincidente con la manera en que distintos sectores castrenses interpretaban la actuación del Poder Judicial respecto al pasado dictatorial, pero también señalaba la preocupación que generaban las audiencias del Juicio por la Verdad en determinados sectores militares y civiles.

Tal como lo había anunciado LNP, ese día, Corres interpuso un recurso procesal con el objetivo de cuestionar el proceso en curso. Finalmente, en horas de la tarde, se presentó ante los jueces del tribunal y fue informado del rechazo de su recurso. Frente a esta situación, Corres se sentó frente a los jueces en el banquillo de los acusados ${ }^{19}$.

Tras brindar juramento, comenzó a responder las preguntas del fiscal. Empezó a "hablar". Inicialmente respondió las preguntas del fiscal acerca de su formación militar y mencionó algunas tareas que le asignaron cuando fue trasladado a Bahía Blanca, desde Tucumán. Con el desarrollo de la audiencia las preguntas del fiscal se orientaron a tratar de establecer el lugar ocupado por el militar en el V Cuerpo de Ejército. Fue en ese marco que, ante una pregunta del Fiscal, el militar confesó su participación en el CCD Escuelita, al afirmar "El jefe de guardia era yo". Pero el reconocimiento de Corres no se limitó a su rol en el CCD Escuelita y ante otra pregunta del fiscal acerca de la identificación de jerarquías al interior del CCD el militar reconoció que "tenían sobrenombres" y señaló que a él le "decían Jefe o Laucha"20. Mediante el reconocimiento de su apodo, Corres, se ubicó como una pieza clave del dispositivo represivo pues el apodo "Laucha" coincidía con el que los sobrevivientes identificaban a uno de los torturadores del CCD Escuelita, del que no sabían el nombre. La declaración de Corres produjo una reactualización de las relaciones sociales que se habían forjado en el terrorismo de Estado, entre víctimas y victimarios, proyectando estas al presente. De esta manera, en la sala de audiencias se produjo la primera metamorfosis de Corres: pasó a ser "El Laucha" y, por ende, un torturador.

Durante el transcurso de la audiencia, las respuestas de Corres fueron transitando desde describir aspectos materiales y precisiones acerca de la organización del CCD Escuelita, de las tareas del personal que allí se desempeñó o manifestar cómo era la vida cotidiana en dicho centro, a negar su participación en hechos y manifestar no recordar nada acerca de lo sucedido (Andriotti Romanin, 2017). Mediante la adopción de esta postura, Corres buscó evitar cooperar sin cometer el delito de falso testimonio. De este modo, podía responder sin confrontar con las declaraciones de otros testigos o evitar referirse a posibles

18- Pocos días antes, el 10 de diciembre de 1999, De la Rúa había asumido como Presidente de Argentina.

19- Tras presentarse ante el tribunal, Corres apeló su citación ante la Cámara de Casación Penal, que era el tribunal de alzada. Este aceptó su queja y reclamó a la CFB el expediente completo de la causa donde se tramitaba el Juicio por la Verdad. Esta medida provocó un conflicto entre ambos tribunales. Al respecto véase Andriotti Romanin (2015).

20- Declaración Julián Oscar Corres, Cámara Federal de Apelaciones de Bahía Blanca, Argentina. (1999, 13 de diciembre). 
pruebas que pudieran incriminarlo en la comisión de crímenes. La postura adoptada frente a las preguntas de los jueces y el fiscal permitió observar que Corres se sentía incómodo y, en cierta forma intimidado frente a la institución judicial pues, aunque gozaba de impunidad, buscó mediante sus respuestas justificar su accionar y exculparse ante éstos. Pero también algo más: la verdad que emergió en este juicio era una verdad incómoda para él, soterrada, que una vez revelada no podría ser ocultada y que tendría efectos. Estos no se hicieron esperar.

Tras la declaración, la fiscalía pidió el careo de Corres con un exconscripto AOR, Alberto Taranto, quien había dicho en su declaración que el militar le mostró en el Hospital Militar los cadáveres de un hombre y una mujer abatidos en un operativo. Esto constituyó una novedad pues, en el marco de este juicio, ninguna de las partes había solicitado un careo entre testigos. La solicitud generó un contrapunto entre el fiscal y el presidente del tribunal acerca de la posibilidad, o no, de implementar este procedimiento en el marco del Juicio por la Verdad. La resolución de esta medida fue parcialmente favorable para la fiscalía, pues el tribunal solo concedió que se preguntara por algunas cuestiones, pero significaba en los hechos que Corres debería volver a la sala de audiencias.

\subsection{La segunda metamorfosis: el abusador}

Al día siguiente de la declaración de Corres, varios diarios nacionales y LNP ampliaron su cobertura acerca de lo ocurrido. Distintas notas se refirieron a los dichos de Corres en la sala de audiencias, difundiendo diferentes interpretaciones sobre lo ocurrido y sobre él. De manera cautelosa, el diario La Nación hizo referencias generales al testimonio de un militar en actividad que describió el CCD Escuelita ( $L a$ Nación, 14/12/99) mientras que el diario Página 12 enfatizó la figura de Corres, su rol como Jefe de seguridad del CCD Escuelita y señaló que el militar reconoció el apodo con el cual era conocido en dicho centro (Página 12, 14/12/99). Por su parte, LNP recogió algunos aspectos de la declaración del militar, enfatizando su presentación contra el accionar de los jueces. En simultáneo, denunció la "parcialidad" de los jueces, destacando que "tal vez existen derechos humanos de primera y otros de décima siendo los primeros objetos de investigación" (LNP, 14/12/99).

La declaración de Corres también fue difundida por las organizaciones de derechos humanos de Bahía Blanca, mediante un boletín destinado a los medios de prensa. Allí resaltaban que el "Juicio por la Verdad había posibilitado conocer el rostro de uno de los ejecutores de la represión del Centro Clandestino La Escuelita”21. En este sentido, la declaración de Corres abrió, para éstos, una oportunidad de ser escuchados dada la gran demanda que tuvieron por parte de los medios de comunicación de la ciudad y del país. Eso les permitió realizar un trabajo de memoria, enmarcando las acciones de este militar y actualizando el pasado en una figura del presente. De esta manera, denunciaban la continuidad de la impunidad de los represores y actualizaban su demanda de justicia.

El 14 de diciembre en horas de la tarde, Patricia Chabat se presentó a brindar testimonio en la sala de audiencias. Chabat narró cómo fue secuestrada el 15 de diciembre de 1976 y trasladada al CCD Escuelita. Durante su testimonio, narró los tormentos sufridos en este centro y reconoció a Corres como el 
torturador apodado como "El Laucha" a quien acusó de haber cometido abusos sexuales contra ella durante su cautiverio ${ }^{22}$. Como un efecto imprevisto de su declaración, una sobreviviente lo había reconocido y ahora "El Laucha" Corres era señalado directamente como el torturador que gozaba sexualmente al infligir sufrimiento físico a las personas secuestradas. Esta acusación, que constituía la primera directa de una sobreviviente contra el militar por abuso sexual en el Juicio por la Verdad, puso en un primer plano a las prácticas de la violencia sexual como una de las torturas a las que habían sido sometidos los detenidos y detenidas en el CCD Escuelita. En este sentido, el escenario judicial permitió la emergencia de una memoria subterránea acerca de un aspecto de la represión que resultaba incómodo para los militares, pero también, en ocasiones, para las y los sobrevivientes ${ }^{23}$ : las violaciones y abusos cometidos en los Centros Clandestinos de Detención. Aunque las prácticas de violencia sexual ya habían sido denunciadas en distintas instancias como parte de las vejaciones sufridas por las y los sobrevivientes, en el ámbito de la justicia penal, estas habían sido subsumidas como parte del delito de tortura. Por ende, la imputación realizada por Chabat en un escenario judicial de amplia visibilidad, permitió proyectar las prácticas de violencia sexual propias del accionar represivo en un perpetrador específico, singularizado. Un militar que tenía nombre y apellido, Julián Corres.

El testimonio de Chabat generó dos reacciones: por un lado, la abogada querellante solicitó que se procesara a Corres por falso testimonio; por el otro, la abogada defensora solicito "por pedido de la testigo" ${ }^{24}$ que se realizará un careo entre ésta y el militar. Ambas reacciones permitieron que desde el escenario judicial se ampliara la visibilidad de un conflicto en torno a la impunidad de los militares. Estas solicitudes asociaban a Corres a la comisión de crímenes aberrantes e interpelaban al Poder Judicial obligándolo a actuar.

El 15 de diciembre, Corres se hizo presente en la sala de audiencia para cumplir con el careo. Antes de comenzar la audiencia, el presidente del tribunal le informó acerca de los hechos sucedidos tras su testimonio. Acto seguido, se leyeron por la secretaria las dos resoluciones del tribunal: Por un lado, los jueces habían decidido dar curso a la denuncia presentada por la querella por falso testimonio y también aceptar el pedido de la abogada defensora de realizar un careo entre él y la testigo Chabat.

La resolución de dar curso a la denuncia por falso testimonio situó a Corres como el primer militar argentino que enfrentó una acusación formal en el marco de los Juicios por la Verdad. Asimismo, modificaba la situación procesal de Corres pues al ser imputado podía negarse a decir la verdad ${ }^{25}$. La imputación de Corres por falso testimonio eximía al militar de confrontar con los otros testigos y, por ello, generó un conflicto entre las partes que integraban la Cámara Federal acerca de la naturaleza y alcance de esta resolución y cómo afectaba la búsqueda de la verdad. La primera reacción provino de

22- Chabat había afirmado por primera vez en 1987, en el marco del testimonio que brindó en la causa 11/86, que había sido torturada por un militar apodado "Laucha".

23- En ocasiones la mención a las violaciones o abusos a los que fueron sometidos los y las sobrevivientes generó un manto de sospecha por parte de actores del Movimiento de derechos humanos respecto a los motivos por los cuales permanecieron con vida. Al respecto véase Longoni, 2007.

24- En el marco de la audiencia del día 15/12/1999 la abogada defensora explicó los fundamentos del pedido al señalar que lo hizo porque tras la audiencia conversó con la testigo a la que le ofreció su ayuda y esta le respondió que "quería encontrase cara a cara con este".

25- Haciendo uso del derecho establecido en el artículo 18 de la Constitución Nacional Argentina. Este artículo establece que nadie puede ser obligado a declarar contra sí mismo. Es importante mencionar que un imputado, tiene el derecho de negarse a declarar mientras que un testigo no lo tiene. 
la fiscalía. El fiscal de la CFB protestó ante la decisión de los jueces de relevar a Corres de decir la verdad sosteniendo que no compartía la denuncia realizada por la querella y advirtió que, de dar curso a la misma, los jueces desnaturalizaban el sentido del juicio por la Verdad. Frente a esta situación, la abogada querellante intento retirar su denuncia y, en simultáneo, apeló al carácter particular de este juicio, solicitando al tribunal "un esfuerzo creativo para adecuar las normas procesales" ${ }^{26}$. Tras un acalorado debate, el presidente del tribunal manifestó que mantendrían su resolución argumentando la necesidad de mantener las garantías individuales del militar y apercibió al fiscal por considerar sus dichos agraviantes.

La nueva situación procesal modificó la naturaleza de la participación de Corres como testigo en el Juicio por la Verdad. Al estar imputado era presumiblemente responsable de un delito y debía enfrentar un proceso que -si bien no estaba ligado a su participación en la represión-, podía conducirlo a la cárcel. Pero a la vez, quedaba relevado de la obligación de decir la verdad. Frente a su nueva situación, el militar solicitó consultar a su abogado ${ }^{27} \mathrm{y}$, con el permiso de los jueces, se retiró de la sala.

Tras un receso, se dio inicio al careo. La primera en ingresar fue Chabat, minutos después ingresó Corres. Los testigos eran ahora careados y sus roles eran otros, el militar acusado de ser presunto victimario y la sobreviviente, su víctima. Así, lo que ocurría en la sala de audiencias implicaba una reorganización simbólica del proceso de búsqueda de la verdad y el escenario judicial se constituía en un escenario de disputa por la verdad entre la víctima y el acusado. En las figuras de Corres y Chabat se personificaba un conflicto irresuelto que atravesaba a la sociedad argentina: por un lado, la victima sobreviviente encarnaba la falta de justicia por los crímenes cometidos durante el terrorismo de Estado y, por el otro, el militar encarnaba la condición de impunidad de que gozaban los militares tras las leyes de impunidad. El careo se constituía así en la posibilidad de una confrontación pública, entre dos verdades acerca de lo acontecido durante el terrorismo de Estado, pero también entre dos posiciones acerca de cómo lidiar con lo ocurrido: por un lado, quienes exigían castigo y por otro, quienes detentaban impunidad. Sin embargo, el militar se negó a realizar el careo. Así, ante la posibilidad de confrontar con la verdad y la memoria de quien lo acusaba, Corres optó por el silencio. Y tras el permiso del presidente del tribunal, Corres se retiró de la sala mientras el público se manifestaba mediante gritos y frases contra su decisión.

La intervención del público introdujo en la sala de audiencias explicaciones acerca del accionar del militar que cuestionaba los atributos personales del militar "cobarde", "ahora no te haces el valiente como cuando la tenías secuestrada", pero también una perspectiva política al señalarlo como "represor", "torturador" o sentenciando "a donde vayan los iremos a buscar". Los gritos de los familiares expresaban la pervivencia de un sentimiento de injusticia en torno a la postura del militar y permitían observar que la participación de Corres en este juicio había potenciado sus demandas de justicia. Aunque en cierta forma Corres había confesado su participación en el sistema represivo, había "hablado" y reconoció haber sido parte del accionar represivo, en virtud de las leyes de impunidad no podía ser juzgado por su participación en el terrorismo de Estado. Por ello, era situado por los familiares en el lugar de acusado y de responsable a la vez, encarnando su figura la condición de impunidad existente. Tras unos minutos,

26- Palabras de Mirta Mantaras, Audiencia del Juicio por la Verdad 15/12/99.

27- Declaración de Julián Oscar Corres, Cámara Federal de Apelaciones de Bahía Blanca, Argentina. (1999, 15 de diciembre) 
Corres fue convocado nuevamente a la sala de audiencias para realizar el segundo careo, al que también se negó. De este modo, finalizó su participación en el Juicio por la Verdad.

Al día siguiente, algunos de los principales diarios del país le dedicaron un espacio en sus páginas a lo que aconteció en la sala de audiencias de la CFB. En la cobertura de los diarios aparecían los nuevos sentidos en torno a la figura de Corres que surgieron del testimonio de Chabat. De esta forma, las representaciones sobre Corres circulaban más allá de la sala de audiencias del tribunal y proyectaban distintas figuras acerca del militar. Por un lado, el diario Clarín mencionó a Corres indicando que se habían referido a él como "El Laucha", "el teniente coronel" y "uno de los interrogadores más despiadados". A su vez, narró el frustrado careo con Chabat, señalando que días antes "La mujer recordó que el militar, por entonces subteniente, había estado presente en varias sesiones de tortura y que incluso había participado de abusos en su contra" y que "el militar no pudo evitar ubicarse durante un par de minutos a sólo un metro de distancia de la mujer que lo identificó como un torturador" (Clarín 16/12/99). Por su parte, Página 12 remarcó la denuncia contra Corres "por haber participado en violación a los derechos humanos" y mencionó los frustrados careos a partir de la identificación de Patricia Chabat y de Alberto Taranto de este como "colaborador activo de La Escuelita" (Pagina 12, 16/12/99). El diario La Nación, que había mencionado la convocatoria a declaración testimonial de Corres, no dedicó ningún espacio a la noticia del careo o a las audiencias del juicio. Finalmente, LNP señaló que "Corres no aceptó los careos" y minimizó las acusaciones de Chabat al señalar que ella denunció "que alguien apodado 'El Laucha' participó de distintas sesiones de tortura a las que había sido sometida", sin hacer referencia a la acusación de abuso sexual, ni al reconocimiento de ese apodo días antes por parte del militar. En simultáneo, las organizaciones de derechos humanos realizaron un balance acerca del desarrollo del juicio que difundieron mediante una conferencia de prensa y en donde señalaron que "un punto central es que las audiencias permitieron desenmascarar al Laucha y conocer el nombre de "una de las bestias de La escuelita".

En las audiencias posteriores del Juicio por la Verdad otros sobrevivientes denunciaron a Corres como el torturador del CCD Escuelita. Aunque el Juicio por la Verdad de Bahía Blanca realizó su última audiencia el 8 de julio de 2000, gracias a lo sucedido en la sala de audiencias el militar conocido como "El Laucha", que hasta entonces no tenía nombre ni rostro, se transformó en una de las figuras de la represión en Bahía Blanca.

Varios años después, tras la reapertura en el año 2006 de los procesos judiciales contra los miembros de las Fuerzas Armadas por los delitos cometidos durante el terrorismo de Estado, Julián "El Laucha" Corres volvería a la CFB. Esta vez como imputado en la causa o 982, donde se investigaron los crímenes de lesa humanidad cometidos en el Vo Cuerpo de Ejército entre 1976 y 1983. En el marco de esta causa, en febrero de 2007 la CFB ordenó su detención, pero el militar logró evitar su captura hasta abril de 2008, donde fue capturado por Interpol. Sin embargo, un mes después de su detención y gracias a la complicidad de efectivos policiales, "El Laucha" logró escapar de la comisaria donde estaba detenido, aunque fue recapturado pocos días después y trasladado a una prisión federal. En 2010 los jueces de la CFB le concedieron el beneficio de cumplir prisión domiciliaria por presentar una enfermedad que exigía cuidados intensivos. Un año después, se inició el juicio de la causa No 982. Sin embargo, Corres no afrontaría el juicio. Moriría impune el 9 de agosto de 2011 a causa de una enfermedad terminal en el Hospital Militar de la ciudad de Buenos Aires, justo mientras se desarrollaba la primera semana de audiencias. 


\section{Conclusión}

A lo largo de este trabajo se indagó en los procesos de lucha política y judicial en torno a las declaraciones de Julián Oscar Corres en el Juicio por la Verdad de Bahía Blanca. En un primer momento se repusieron los distintos actores que contendieron en torno a este juicio. Por un lado, se observó la existencia de organizaciones que nucleaban a sobrevivientes y familiares de detenidos desaparecidos, y su posición favorable al desarrollo del mismo. Frente a estos, se observaron distintos actores, entre los que se destacó el diario La Nueva Provincia. Se pudieron establecer las acciones realizadas en torno a la puesta en marcha de este juicio, y en su desarrollo, destacándose la reticencia de los militares a participar en las audiencias y la puesta en marcha de una estrategia política y judicial tendiente a cuestionar el desarrollo del Juicio por la Verdad.

En un segundo momento se analizaron las declaraciones de Julián Oscar Corres donde el militar reconoció su rol en el CCD Escuelita y su apodo. Se pudo observar que este reconocimiento generó efectos, aun cuando no se lo podía perseguir penalmente dadas las leyes e indultos que lo impedían, y la continuidad de tensiones existentes en la sociedad argentina acerca de cómo lidiar con el pasado.

Finalmente, se analizó la disputa por la verdad que se desarrolló en el marco de las audiencias y su incidencia en la construcción social de la figura del "represor". Por un lado, los dichos del militar permitieron que los profesionales del derecho pusieran en marcha distintas acciones tendientes a lograr que este continuara brindando testimonio. Por otro lado, generaron que se incrementara la cobertura periodística en torno a la declaración de Corres en virtud de las reacciones y conflictos que ésta generó (en especial la confrontación con una testigo sobreviviente que lo acusó de haber abusado sexualmente de ella durante su cautiverio en el CCD Escuelita), que produjeron como resultado la construcción de una compleja representación acerca de la figura de Corres como "torturador". Esta última, que fue promovida por distintas organizaciones del movimiento de derechos humanos, adquirió amplia difusión y visibilidad mediática y contribuyó a complejizar la memoria social acerca del terrorismo de Estado en Bahía Blanca.

\section{Referencias}

Andriotti Romanin, E. (2013). Decir la verdad, hacer justicia. Los Juicios por la Verdad en Argentina. European Review of Latin American and Caribbean Studies, (94), 5-23. DOI: https://doi.org/10.18352/ erlacs.8389

Andriotti Romanin, E. (2015). Enfrentando el pasado en tiempos de impunidad. Las estrategias de los militares en el Juicio por la Verdad de Bahía Blanca (1999 - 2000). Clepsidra. Revista interdisciplinaria de estudios sobre memoria, 2 (4), 116 -133.

Andriotti Romanin, E. (2017). Reconocer, negar y olvidar. Las declaraciones del represor Julián "el Laucha" Corres en el Juicio por la Verdad de Bahía Blanca. Atheleia, 7 (14), 1-10.

Badaró, M. (2009). Militares o ciudadanos. La formación de los oficiales del Ejército Argentino. Prometeo.

Canelo, P. (2010). La responsabilidad y la convicción. Las "autocríticas" del general Balza y su impacto en la interna militar argentina durante los años noventa. Militares e política, (7), 100-116. 
Cámara Federal de Apelaciones de Bahía Blanca, Argentina. (1999, 29 de noviembre). Filmación audiencia de Juicio por la Verdad testimonio de Alberto Taranto. Memoria Abierta. http://archivos. memoriaabierta.org.ar/index.php/fondo-audiovisual-juicio-por-la-verdad-bah-a-blanca

Cámara Federal de Apelaciones de Bahía Blanca, Argentina. (1999, 13 de diciembre). Filmación audiencia de Juicio por la Verdad testimonio de Julián Oscar Corres. Memoria Abierta. http://archivos. memoriaabierta.org.ar/index.php/fondo-audiovisual-juicio-por-la-verdad-bah-a-blanca

Cámara Federal de Apelaciones de Bahía Blanca, Argentina. (1999, 14 de diciembre). Filmación audiencia de Juicio por la Verdad testimonio de Patricia Chabat. Memoria Abierta. http://archivos.memoriaabierta.org.ar/index.php/fondo-audiovisual-juicio-por-la-verdad-bah-a-blanca

Cámara Federal de Apelaciones de Bahía Blanca, Argentina. (1999, 15 de diciembre). Filmación audiencia de Juicio por la Verdad careo entre Julián Corres y Patricia Chabat y palabras de Mirta Matnaras y Alberto Cotter. Memoria Abierta. http://archivos.memoriaabierta.org.ar/index.php/ fondo-audiovisual-juicio-por-la-verdad-bah-a-blanca

Feierstein, D. (2015). Juicios sobre la elaboración del Genocidio II. Fondo de Cultura Económica.

Feld, C. y Salvi, V. (2016). Presentación. Cuando los perpetradores hablan. Dilemas y tensiones en torno a una voz controvertida. Rubrica Contemporánea, 5 (9), 1-10. DOI: https://doi.org/10.5565/rev/ rubrica.116

Feld, C. y Salvi, V. (2019). Introducción. Declaraciones públicas de represores de la dictadura argentina. En Feld, C. y Salvi, V, Las voces de la represión. Declaraciones de Perpetradores de la dictadura Argentina (pp.11-34). Miño y Davila.

Filipini, L. (2011). La persecución penal en busca de justicia. En Centro de Estudios legales y Sociales, Hacer Justicia. Nuevos debates sobre el juzgamiento de crímenes de lesa humanidad en Argentina (pp. 19-47). Siglo veintiuno editores.

Foucault, M. (2011). La verdad y las formas jurídicas. Gedisa.

Garvian, S. (2016). La muerte del verdugo. Reflexiones interdisciplinarias sobre el cadáver de los criminales. Miño y Davila.

Hershberg, E. y Agüero, F. (2005). Las Fuerzas Armadas y las memorias de la represión en el Cono Sur". En Hershberg, E. y A., Felipe (comps), Memorias Militares sobre la represión del Cono Sur: visiones en disputa en dictadura y democracia (pp. 1-34). Siglo veintiuno editores.

Lorenz, F. (2002). ¿De quién es el 24 de marzo? Las luchas por la memoria del golpe del '76. En: Jelin, E. (comp) Las conmemoraciones: las disputas en las fechas "in-felices" (pp. 53-100). Siglo Veintiuno editores.

Lorenz, F. (2007). Combates por la memoria. Huellas de la dictadura en la historia. Capital Intelectual.

Marchesi, A. (2005). Vencedores vencidos: la respuesta de los militares frente a los informes Nunca Más. En Hershberg, E. y A., Felipe (comps), Memorias Militares sobre la represión del Cono Sur: visiones en disputa en dictadura y democracia (pp. 175-207). Siglo veintiuno editores.

Jelin, E. (2011). Dilemas actuales: Los abusos sexuales como crímenes de lesa humanidad y el respeto a la intimidad. Lucha Armada en la Argentina, (6): 10-22.

Longoni, A. (2007). Traiciones. La figura del traidor en los relatos acerca de los sobrevivientes de la represión. Norma editorial.

Palacio Lino, E. (2000). La prueba en el proceso penal. Abeledo-Perrot. 
- Revista de Ciencias Sociales y Humanidades. ISSN-P: 0188-9834 ISSN-E:2395-8669.

Pollak, M. (2006). Memoria, olvido, silencio. La producción social de identidades frente a situaciones límite. Al Margen.

Rauschenberg, N. (2013). Memoria política y justicia transicional en Argentina después de treinta años de democracia. Notas para un debate. Aletheia, 3(6), 1-19.

Robben, A. (2008). Pegar donde más duele. Violencia política y trauma social en Argentina. Anthropos.

Salvi, V. (2012). De vencedores a víctimas. Memorias militares sobre el pasado reciente en la Argentina. Biblos.

Taylor, S. J. y Bogdan, R. (1987). Introducción a los métodos cualitativos de investigación. Paidós.

Vezzetti, H. (2002). Pasado y Presente. Guerra, dictadura y sociedad en la Argentina. Siglo Veintiuno Editores.

Zapata, A. B. (2016). El pasado reciente entre Historia y Justicia: Un análisis sobre el rol de empresarios en dictadura, a propósito de la causa Massot. Atheleia, 7(13), 1-24. 